\title{
Editorial
}

\section{Simulation Modelling}

\section{Associate Editors: Simon J E Taylor and Stewart Robinson}

\begin{abstract}
The Editors are pleased to offer this opportunity for the associate editors for Simulation Modelling to outline issues of current inlerest in the domain, and seek contributions from potential authors.
\end{abstract}

Simulation has been a major discipline for members of the business, academic, and defence communities for over 30 years and has been widely used in decision support systems across many industries (manufacturing, scrvice, defence, etc) when either direct experimentation is too costly or dangerous, or when mathematical modelling cannot capture the required level of system detail. The process of simulation consists of many activities such as problem definition, model building, and experimentation. Problem definition specifies the problem that is to be investigated (production efficiency, scheduling strategies, command and control doctrine, etc). Model building involves the conceptualisation, specification, verification, and validation of a model (manufacturing system, air traffic control system, battle, etc) within a programming language or commercial off-the-shelf (COTS) simulation package. Experimentation (and possibly optimisation) involves running the model with different sets of parameters to investigate the defined problem. Supporting technologies such as the Internet, the World Wide Web, groupware, and parallel and distributed computing have sometimes been used to augment the simulation process.

The UK boasts a strong community of practitioners and researchers in simulation modelling. In recent years, the Simulation Study Group of the Operational Research Society has supported this discipline with well attended one-day meetings dedicated to many diverse areas of interest within Simulation Modelling, a special issue of the Journal of the Operational Research Society (Taylor, Paul and Robinson 2000), the development of an EPSRC Technology Programme Network dedicated to the study of collaborative simulation modelling (GROUPSIM $^{1}$, and a forthcoming two-day
Simulation Workshop to be held in March $2002^{2}$.

To continue these activities, the associate editors in Simulation invite papers on all aspects of simulation modelling. All submissions will be considered but particular emphasis is placed on case studies that may be used as exemplars of good practice in the field. State-of-the-art reviews and surveys, with a focus on the practical application of simulation, are also welcome in areas such as:

- Component based simulation

- Collaborative design

- Parallel and distributed simulation

- Web based simulation

- Simulation and artificial intelligence

- Simulation software

- Conceptual modelling

- Input analysis

- Verification and validation of simulation models

- Output analysis

When submitting your paper, please remember to address the general aims of OR Insight, which can be found on the back page, together with formatting instructions. Please send any electronic copy of papers on simulation to Simon Taylor (simon.taylor@brunel.ac.uk) or Stewart Robinson (stewart.robinson@warwick.ac.uk)

As a final note the Simulation Study Group actively welcomes participation. If you have a simulation area that you would like the group to consider as a topic for a meeting, please contact Simon or Stewart at the above addresses for more information.

\footnotetext{
${ }^{1}$ See www.brunel.ac.uk/ csstsjt/groupsim.htm for details of how to get involved.

${ }^{2}$ See http://www.orsoc.org.uk/conf/index f.html for details and the call for papers.
} 